\title{
A FEBRE AMARELA E A NECESSIDADE CONSTANTE DE VIGILÂNCIA EPIDEMIOLÓGICA
}

\section{ARTIGO ORIGINAL}

GITIRANA, José Valdeci Almeida ${ }^{1}$

GITIRANA, José Valdeci Almeida. A Febre Amarela e a necessidade constante de vigilância epidemiológica. Revista Científica Multidisciplinar Núcleo do Conhecimento. Ano 04, Ed. 11, Vol. 06, pp. 05-15. Novembro de 2019. ISSN: 24480959, Link de acesso: https://www.nucleodoconhecimento.com.br/saude/febre$\underline{\text { amarela }}$

\section{RESUMO}

Objetivo: desvelar os fatores que justificam a importância de uma vigilância epidemiológica eficiente para o controle da febre amarela no país. Método: pesquisa exploratória, bibliográfica, qualitativa e descritiva. Resultados: os últimos levantamentos epidemiológicos indicam que o número de casos de febre amarela silvestre registrada no Brasil é muito variável, assim, se for considerado que para cada caso detectável ocorram outros 10 de evolução subclínica, as cifras reais podem ser bem maiores que as registradas pelos órgãos de saúde. Conclusão: A febre amarela, como uma doença infecciosa aguda, constitui-se como uma zoonose de difícil controle, pois é capaz de provocar epidemias imprevisíveis em populações humanas, exemplo é o momento vivido pelo Estado de Minas Gerais, que sofre com um surto da doença, motivada por condições de desequilíbrio ambiental que favorecem ao desenvolvimento e a proliferação dos vetores, cooperando para a ocorrência de centenas de óbitos apenas nos primeiros meses de 2017.

\footnotetext{
${ }^{1}$ Especialista em Análises clínicas, Graduado em Farmácia, Atualmente acadêmico de medicina.
} 
Descritores: controle, febre amarela, diagnóstico, vigilância epidemiológica.

\section{INTRODUÇÃO}

A febre amarela é uma doença infecciosa aguda, que constitui um sério problema de saúde pública na maioria dos países tropicais, onde as condições do meio ambiente favorecem o desenvolvimento e a proliferação dos vetores, causando dezenas de casos de óbitos anualmente. Pode se apresentar sob formas leves ou subclínicas e até formas graves caracterizadas pela tríade constituída por icterícia, hemorragias e insuficiência renal aguda, com um índice de mortalidade, nos casos graves, entre 20 a $50 \% .{ }^{24}$

O agente etiológico dessa doença é um arbovírus de RNA pertencente à família Flaviviridae. Este vírus se mantém na natureza em um ciclo silvestre, tendo primatas como reservatório e mosquitos do gênero Hemagogos como vetores, e outro urbano, no qual o reservatório é o próprio homem e tem o mosquito Aedes aegypti como vetor, neste caso específico a doença é transmitida do homem doente ao homem não imunizado através da picada do vetor. ${ }^{25}$

Clinicamente, o período de incubação é normalmente de três a seis dias. Contudo, períodos mais longos já foram descritos. O espectro clínico da doença varia desde um quadro benigno, caracterizado por doença febril não específica, até uma doença fulminante, caracterizada por disfunção de múltiplos órgãos, em particular por hemorragias ${ }^{1}$. Assim, o paciente pode passar por um período assintomático, com posterior febre, cefaleia, dores musculares generalizadas, fotofobia, calafrios, icterícia, podendo evoluir com quadro hemorrágicos e insuficiência renal aguda ${ }^{2,3}$.

A febre amarela é uma doença de notificação compulsória e todos os casos suspeitos devem ser confirmados laboratorialmente. O diagnóstico deve ser consubstanciado através de dados epidemiológicos, nas manifestações clínicas descritas para as várias formas, e em dados laboratoriais. Contudo, um diagnóstico mais preciso é obtido através da pesquisa sorológica de anticorpos específicos e análise histopatológica e imuno-histoquímica dos espécimes de fígado ${ }^{4}$. Do ponto de vista patogenético, lesões 
podem ser observadas no fígado, rins, coração, baço e linfonodos ${ }^{1}$, no entanto, a lesão mais importante dessa doença ocorre no fígado, ao nível dos hepatócitos.

O vírus causador da febre amarela está classificado taxonomicamente família Flaviviridae, gênero Flavivirus. Os flavivirus são esféricos, envelopados, e medem aproximadamente 40-50 nm. Seu genoma (RNA) é constituído por uma fita única, linear, não segmentada, apresentando coeficiente de sedimentação de 44S, contendo aproximadamente 10.0862 nucleotídeos, peso molecular de 4 x 106 kd, Possuem 10 genes, que irão codificar 10 proteínas: três estruturais, as proteínas $\mathrm{C}, \mathrm{M}$, E; e sete não-estruturais, as proteínas NS1, NS2a, NS2b, NS3, NS4a, NS4b e NS5 ${ }^{5}$.

A proteína $\mathrm{C}$ pode ser no capsídeo viral. As proteínas $\mathrm{M}$ e $\mathrm{E}$ são constituintes do envelope viral. A proteína E é glicosilada e tem importantes determinantes antigênicos, principais responsáveis pela indução da resposta imune e possui, também, considerável valor para a ligação do vírus com o receptor de membrana do hospedeiro. A proteína M (não glicosilada) é resultante da clivagem da proteína pré$M\left(\right.$ glicosilada) ${ }^{1}$.

Contudo, existem trabalhos que têm salientado também a importância das proteínas NS1 e NS3 na resposta imunológica do hospedeiro. A primeira tem capacidade de ativar complemento e induzir a lise de células infectadas, enquanto a NS3 se constitui em um dos principais alvos de ataque dos linfócitos T citotóxicos ${ }^{6}$.

Após a penetração das partículas virais no citoplasma e o desnudamento, o RNA se replica em regiões perinucleares, intermediados por um RNA de polaridade negativa. A maturação dos vírions ocorre em membranas intracelulares, com o vírus brotando a partir do aparelho de Golgi ou do retículo endoplasmático, sendo que dois tipos distintos de partículas virais podem ser definidos: os vírus associados às células e as partículas virais extracelulares. ${ }^{26}$

Os vírus pertencentes à família Flaviviridae têm capacidade de se replicar tanto em mosquitos quanto em primatas, dentre eles o homem. Possuem grande capacidade 
de adaptação, o que implica dizer que tal característica tem relação direta na manutenção dessas viroses na natureza. ${ }^{27}$

A partir de um critério eminentemente epidemiológico, se pode definir o vírus da febre amarela como um arbovírus cujo ciclo primário envolve primordialmente, mosquitos da floresta e espécies de primatas não-humanos, principalmente os Callitrichidae e Cebidae, sendo que dentre os primatas neotropicais, a maioria das espécies da América do Sul quando infectados, em geral, apresentam evolução fatal, fato este não observado em espécies africanas. Da mesma forma, espécies como pássaros, roedores, marsupiais, carnívoros, anfíbios e répteis são em geral resistentes ao vírus da febre amarela ${ }^{7}$.

Os mosquitos envolvidos como vetores da febre amarela são antropofílicos de atividade diurna nas copas das árvores, em meio silvestre e por isso a infecção humana é acidental e consequente à penetração humana no local onde ocorre a zoonose. Já no meio urbano faz-se necessária a presença de vetores vivendo no domicílio ou peridomicílio do homem urbano ${ }^{1}$.

Diversas espécies de vetores desta patologia foram estudadas ao longo dos anos e podem variar conforme a região investigada, dentre elas podemos citar: Haemagogos janthimomys, Haemagogus albomaculatus e leucocelaenus, $\mathrm{Hg}$. janthinomys, Sabethes chloropterus e Sabethes soperi, Aedes abopictus e Aedes aegypti, entre outros. ${ }^{28}$

Do ponto de vista da transmissão o homem tem importante papel na disseminação do vírus para áreas onde este não ocorre naturalmente, mas que possuem vetores e macacos, que fazem parte do ciclo de transmissão da doença. Além disso, modificações na floresta, em geral provocada pela abertura de estradas, atividade madeireira e de agricultura, expõem acidentalmente indivíduos não imunizados a vetores invertebrados selvagens, sendo uma das principais formas de transmissão da doença na Amazônia brasileira ${ }^{3,4}$. 
Vale lembrar que, mesmo não prevalente em nosso meio, outra forma de manutenção do vírus na natureza pode ocorrer em zonas urbanas, sendo o Aedes aegypti o vetor envolvido e o homem o único hospedeiro. A forma urbana da febre amarela foi erradicada do Brasil em 1942. Entretanto estudos têm demonstrado a presença do Aedes aegypti em cerca de 21 estados brasileiros ${ }^{7}$.

Assim sendo, um paciente virêmico proveniente de uma área endêmica de febre amarela silvestre pode, associado às altas densidades do Aedes aegypti, se constituir em potencial estímulo para reurbanização da febre amarela, o que traria consequências sérias principalmente para a população não imunizada previamente 7,4 .

Estudos têm levantado a hipótese de possível participação do Aedes albopictus no ciclo de transmissão da doença, cuja capacidade de transmitir o vírus já foi demonstrada em laboratório ${ }^{1,8,9}$. Devido ao fato desse agente poder se procriar em ambientes rurais, peri-urbanos e urbanos, potencialmente poderá servir de ponte entre o ciclo silvestre e urbano da febre amarela. Na África, várias espécies do gênero Aedes, como Aedes furcifer, Aedes taylorie Aedes luteocephalus, são tão importantes vetores urbanos quanto o Aedes aegypti ${ }^{5}$.

A resposta à infecção amarílica é ampla e variável, nesta perspectiva, estima-se que cerca de $90 \%$ dos casos com expressão clínica sejam das formas classificadas como leve e oligossintomática, ou seja, apresentando poucos sintomas e que somente $10 \%$ sejam das formas graves. Além disso, há pessoas que desenvolvem quadros assintomáticos ${ }^{8}$.

Tais formas assintomáticas, bem como os casos subclínicos e as formas leves da doença costumam ser perceptíveis em crianças de baixa idade cujas mães foram vacinadas e Ihes transmitiram anticorpos maternos do tipo $\operatorname{lgG}{ }^{9}$. Por outro lado, há indivíduos que desenvolvem formas mais severas da doença, como por exemplo, as pessoas que nunca foram vacinadas e, por isso, estão completamente indefesas à doença. Estes indivíduos, por sua vez, desenvolvem quadros clínicos severos e extremamente graves da enfermidade. 
Vale ressaltar que nas formas leves e moderadas da doença a sintomatologia é indiferenciada e não característica, ou seja, se confunde com muitas doenças comuns nas áreas endêmicas, como por exemplo, a malária, as hepatites virais, a febre tifoide, dentre outras ${ }^{10}$.

Em geral, os sintomas na forma leve se restringem a cefaleia e astenia, acompanhada de febrícula ou de moderada febre. Evolui por até dois dias, após findar estes o paciente se recompõe sem mostrar sequelas. Em sua forma moderada, o paciente além poder apresentar esses sintomas pode inclusive vir acompanhado de náuseas com ausência de vômito, além de mialgias e artralgias que não chegam a incomodar o paciente e nem impedem sua locomoção.

A cefaleia costuma ter duração maior. A febre só finda com o uso de antitérmicos e a astenia já mais persistente. É acompanhado desse quadro sintomático pelo menos um dos indícios clássicos da doença: icterícia ou oligúria/anúria e hematêmese (vômito negro) ${ }^{8}$. A duração de tal estado é de dois a três dias e a recuperação é integral. O quadro evolui em dois períodos, com uma fase de remissão entre eles. Ressalte-se, no entanto, que nem sempre é possível se separar tais fases. ${ }^{8}$

A sintomatologia da forma clássica da febre amarela é grave e caracterizada por um início abrupto, após um período de incubação médio de 6 dias (período que vai desde picada infectante ao início da manifestação dos sintomas) e que pode durar cerca de duas semanas. De início surge febre elevada, na qual o paciente informa ter se sentido bem e concluído suas ocupações algumas horas antes ${ }^{8}$. A febre é desacompanhada de aumento da pulsação ${ }^{11}$.

Contrariamente, é comum se observar febre alta com queda da pulsação, tal sinal é conhecido como sinal de Faget ${ }^{12}$. Pouco tempo após o aparecimento da febre manifesta-se a cefaleia holocraniana de tal intensidade que 0 paciente frequentemente sente necessidade de solicitar o uso de analgésicos ${ }^{13}$. 
Acompanham esse quadro dores musculares difundidas, especialmente nas costas, onde costumam estar presentes. Astenia, prostração e náuseas finalizam esse quadro que evolui de 2 a 3 dias e condiz com o período prodrômico ${ }^{8}$.

Em diversos pacientes, evoluindo-se ao período infeccioso, existe uma fase de melhora que se caracteriza por sensação de alívio e cura imediata por parte do paciente, pois a febre baixa ou então cessa, as dores musculares diminuem e a cefaleia passa para um estado suportável.

Este período tem duração de 12 até 48 horas e, após isso, contrariamente dos indivíduos que desenvolvem as formas leves e moderadas que de fato curam, o estado desses pacientes subitamente se agrava, com a piora de todos os sintomas antes apresentados, junto do surgimento de outros ${ }^{11}$. Este sinal é o início do período de intoxicação, toxêmico ou "fase de localização", pois neste período o vírus passa de circular no sangue para ser localizado somente no fígado. Nele as náuseas se intensificam e vômitos surgem abruptamente. Estes sintomas de início são alimentares e depois, amplamente hemorrágicos ${ }^{12}$.

Os vômitos são cor de borra de café caso o sangue tenha sofrido reação do suco gástrico, ou amplamente hemorrágico caso o sangramento seja recente ou intenso. Evidencia-se que outras manifestações hemorrágicas são comumente encontradas. As hemorragias mais presentes são do tecido tegumentar, das gengivas e do ouvido ${ }^{14}$. No trato gastrintestinal pode vir a ocorrer melena, quando a hemorragia estomacal é ampla ou quando apresenta a manifestação de sangramento do intestino ${ }^{15}$.

Acompanhando ou até antecedendo as hemorragias, há presença de plaquetopenia, muitas vezes tão intensa que pode chegar a menos de $20.000 / \mathrm{mm} 3$ de sangue. É interessante evidenciar que alguns pacientes, mesmo com tais níveis de plaquetas, não sangram. Enquanto outros que apresentam taxas entre 50.000 a 100.000 plaquetas manifestam hemorragias exorbitantes. Percebe-se que nem sempre a grau de intensidade da hemorragia está interligada com a contagem das plaquetas ${ }^{14}$. 
Junto desses sintomas surge a icterícia, a existência da cor amarelada na pele e nas escleróticas dos olhos ${ }^{14}$. A icterícia é, em suma, do tipo verdínica e deve-se ao fato do aumento da fração direta ${ }^{8}$. Em torno do $5^{\circ}$ ao $7^{\circ}$ dia do período de estado, instalase a insuficiência renal, que se apresenta inicialmente pela diminuição do volume urinário e, caso não tratada celeremente pode desencadear anúria e parada completa da diurese, devido à necrose tubular aguda amplamente espalhada que se instala. Este é o momento em que mais frequentemente vem a ocorrer os óbitos ${ }^{11,12}$.

Os que sobrevivem recuperam-se lentamente, mas totalmente e sem sequelas. Durante a convalescênça, indisposição, astenia e dores musculares costumam estender-se por até duas semanas.

Vale frisar que na África são reportados com frequência a ocorrência de formas fulminantes, os quais se caracterizam com uma evolução de até três dias, decorrentes de insuficiência renal e, quase sempre, sem a presença de icterícia ou mesmo alterações hepáticas ${ }^{16}$.

No outro extremo, se podem destacar os raros casos de óbito tardio em decorrência da febre amarela, casos que têm associação com lesões cardíacas tardias ${ }^{17}$. Finalmente, não se pode deixar de frisar que nos casos em que a icterícia é abrupta e os níveis séricos de bilirrubina são muito altos a encefalopatia se mostra frequente, sendo um sinal de mau prognóstico. No entanto, a maioria dos pacientes evolui a óbito ou por insuficiência hepatorenal ou em decorrência das hemorragias, as quais muitas vezes são incontroláveis.

O exame específico para o diagnóstico definitivo da febre amarela é o isolamento do vírus, também chamado de exame de cultura. Através deste exame é possível a detecção de antígenos virais e do RNA viral ${ }^{9}$. Além disto, é possível diagnosticar a doença através do emprego de métodos sorológicos, como por exemplo, a dosagem de anticorpos específicos pelo método de MAC ELISA por meio da captura de lgM em ensaio enzimático ou pela conversão sorológica em testes de inibição da hemaglutinação $(\mathrm{IH})^{18}$. 
Nesta perspectiva, o isolamento do vírus pode ser feito combinando diferentes sistemas, como por exemplo, no caso do isolamento do vírus este só será possível após a inoculação da amostra suspeita, momento em que se obtêm indícios da replicação viral em torno do $5^{\circ}$ ao $7^{\circ}$ dia de cultura. Assim, ao ser separada, a amostra viral poderá ser identificada em testes de imunofluorescência indireta, usando-se de anticorpos monoclonais ou alternativamente mediante testes de fixação do complemento ${ }^{16}$.

Por outro lado, os métodos sorológicos que apontam IgM específica, como acontece com o caso do MAC ELISA, podem dar um diagnóstico presuntivo ágil com uma amostra sorológica, se ela for coletada do paciente a partir do $5^{\circ}$ dia de doença ${ }^{19}$. Assim, a manifestação de lgM pode ser resultante de infecção recente (2-3 meses) ou corrente (vigente), por esse motivo a importância de ter-se a história epidemiológica e clínica completa para a interpretação do resultado laboratorial. Importante destacar que a vacinação antiamarílica pode fomentar a formação de $\operatorname{lgM}$ e, por isso, é de extrema relevância saber os antecedentes vacinais do paciente.

Como ainda não existe um fármaco específico e eficaz para o tratamento dessa moléstia, os exames que diagnosticam como positiva para a infecção demoram em torno de uma semana. O tratamento de suporte deve ser iniciado imediatamente, sendo enfático o internamento do paciente com as formas graves em hospitais com bom preparo infraestrutural para qualquer doença e de preferência em UTI, uma vez que existe a necessidade de uma série de procedimentos que só se delibera mais facilmente nessas unidades ${ }^{12}$.

No entanto, o tratamento medicamentoso só deve ser focado para combater os sintomas, assim, a medicação a ser prescrita depende das manifestações clínicas do paciente, mas é habitual o uso de antitérmicos e analgésicos nas doses comumente indicadas, variando de acordo com fatores como a idade e o peso dele.

Vale destacar a contraindicação do uso de medicamentos que possuem em sua fórmula o ácido acetilsalicílico ou seus derivados, vez que este poderão agravar os fenômenos hemorrágicos que podem estar associados à evolução da doença ${ }^{8,11}$. 
Havendo a ocorrência de vômitos, medicamentos controladores como, por exemplo, a metoclopramida são comuns. Além disto, é recomendado o uso de medicamentos para preservar a mucosa gástrica, chamados de bloqueadores $\mathrm{H} 2$, como a cimetidina e a ranitidina, tendo estes como exemplo, que são extremamente úteis para prevenir os sangramentos gástricos. Estes sangramentos podem se consolidar como uma das mais fatais complicações da febre amarela. Quando é evidenciada a insuficiência renal através da oligúria é importante que deva ser prescrito fármacos diuréticos ${ }^{19}$.

Não se pode deixar de enfatizar que a avaliação do paciente deve ser constante e inclui ações como a averiguação dos sinais vitais, da diurese, e a solicitação de no mínimo os seguintes exames: hemograma, plaquetas, sumário de urina e verificação das funções hepática (dosagem das aminotransferases, bilirrubina e gama GT) e renal (dosagem de ureia e creatinina, e monitoramento do balanço hídrico $)^{19}$. Assim, diante de quadros em que pacientes apresentem insuficiência renal instalada e não responda aos diuréticos comuns é importante que se indique a hemodiálise ou a diálise peritoneal, dependendo da evolução do paciente e considerando o agravamento do quadro.

\section{MÉTODO}

A febre amarela foi no passado como um grande martírio para a população brasileira e ainda hoje, apesar da existência da valina antiamarílica, é motivo de preocupação. Sobretudo, pela gravidade que pode alcançar e podendo inclusive evoluir a óbito. É uma doença infecciosa aguda, que constitui um sério problema de saúde pública em muitos dos países tropicais, onde as condições ambientais favorecem o desenvolvimento e a reprodução dos vetores. Seu agente etiológico é um arbovírus de RNA pertencente à família Flaviviridae. ${ }^{4}$ Neste trabalho, lança-se uma visão abrangente sobre as várias formas de enfrentamento deste grande problema de saúde pública e sobre a importância de seu controle através de um sistema de vigilância da febre amarela eficiente.

Sendo assim, esta pesquisa foi realizada em caráter qualitativo ${ }^{22}$ já que aborda a febre amarela, enfatizando a necessidade de constante vigilância epidemiológica. 
Nesta perspectiva, este artigo é apresentado em forma descritiva, tendo como base o respeitante teórico utilizado na pesquisa, relatando as características principais da patologia, as quais firmam a necessidade da vigilância no país por meio de ações que enfatizem a prevenção.

\section{RESULTADOS}

A febre amarela é doença de notificação obrigatória e, como tal, qualquer caso com suspeita deve ser imediatamente comunicado à autoridade sanitária local, estadual ou nacional, que por sua vez tem o dever de reportar o caso aos organismos internacionais ${ }^{20}$.

Caso seja confirmado ou descartado laboratorialmente, a notificação do caso é passada à autoridade nacional, que por sua vez confirma ou descarta a intimação à autoridade sanitária internacional. Isto deve ser feito sempre para agilizar as medidas preventivas e precaver possíveis surtos ${ }^{21}$.

Importante ressaltar que o método mais eficiente para se prevenir a ocorrência de febre amarela ainda é a vacinação com a amostra 17D. Nesta perspectiva, advertese que sejam devidamente vacinadas todas as pessoas hígidas com mais de seis meses de idade, que estejam expostas ou que venham a se expor à possíveis contaminações por infecção ${ }^{8,10,16}$.

Uma única dose da vacina protege o indivíduo por pelo menos 10 anos, período em que se recomenda a revacinação. Contudo, vale enfatizar que alguns estudos demonstraram que pessoas vacinadas apenas uma vez e vivendo longe das áreas de risco, apontam anticorpos neutralizantes por até 35 anos, o que denota a confiabilidade e a eficácia da vacina ${ }^{16}$

Considerando-se o fato de que a vacina é produzida com o vírus vivo atenuado, não é aconselhável que pessoas com imunodeficiência aos riscos de reversão da virulência em um hospedeiro com depressão do sistema imune sejam vacinadas ${ }^{29}$. 
Pacientes com câncer, SIDA/AIDS e em uso de medicação que diminui a resposta imune do organismo não devem ser vacinados, a não ser em casos especificamente predeterminados pela autoridade médica ${ }^{8}$.

Portanto, além da vacinação, o combate aos vetores e o uso de proteção individual são formas de prevenção da febre amarela, mas não se deve perder de vista que o combate aos vetores silvícolas é basicamente inviável, de modo que o combate ao vetor urbano se torna relativamente fácil ${ }^{29}$.

\section{DISCUSSÃO}

Considerando o recente surto de febre amarela silvestre que assola a zona rural do Estado de Minas Gerais e se espalha pelo país é inegável enfatizar que é dever da coordenação do Programa de Vigilância e Controle de Febre Amarela (PVCFA) encontrar soluções para aprimorar e sofisticar a vigilância da doença no território nacional, dentre as ações que englobam tal dever estão: definir áreas de risco, possibilitar que os laboratórios tenham meios para identificar casos da doença, promover ações de educação sanitária a fim de conscientizar a população acerca da necessidade da prevenção, dentre outras. Contudo, algumas medidas ${ }^{23}$ deveriam ser dotadas de modo a tornar a vigilância epidemiológica no Brasil em relação à febre amarela mais eficaz, como por exemplo:

- Adotar uma definição de caso mais aberta do que aquela aconselhada pela Organização Pan Americana de Saúde (OPAS), de preferência introduzindo uma abordagem sindrômica, com a finalidade de aumentar a receptibilidade e utilidade do sistema ${ }^{20}$;

- Melhorar a qualificação da informação para aumentar a conveniência do sistema em analisar e detectar tendências históricas ${ }^{20}$;

- Evoluir o sistema de vigilância de epizootias e entomológica como eixos primordiais da detecção precoce da circulação viral no Brasil, sobretudo em áreas onde a população residente ainda não é vacinada ${ }^{20}$; 
- Integrar conhecimentos, novas técnicas e tecnologias para o alcance das premissas do programa, como a utilização de informações geográficas para detectar possíveis tendências da distribuição e dispersão viral e verificar correlação com dados ambientais, entomológicos e demográficos, enfatizando desenvolver um modelo capaz de calcular áreas de risco para febre amarela ${ }^{20}$.

Vale frisar que, embora a última manifestação da febre amarela urbana tenha sido documentada há mais de 60 (sessenta) anos no país, não se pode desconsiderar a possibilidade de reemergência. Sobretudo quando fatores potencialmente favoráveis podem ser identificados facilmente ${ }^{14}$.

Um destes fatores é justamente a dispersão do Aedes aegypti em milhares de municípios, o que enseja dos órgãos competentes a necessidade de buscar novas possibilidades para a saúde pública. Especialmente de ordem sanitária ${ }^{23}$.

Além disso, não se pode deixar de enfatizar o fato de que a manutenção da proliferação da febre amarela silvestre é um intento à saúde da população. Sobretudo devido a capacidade epidêmica que pode assumir em populações urbanas que apresentem índices menores que $50 \%$ de cobertura vacinal ${ }^{223}$.

Em suma, a junção dessas ideias indica que a vigilância de febre amarela deve trabalhar lado a lado da vigilância de casos humanos, da vigilância de epizootias em primatas não humanos e da vigilância entomológica, com vistas a aumentar a eficácia para a detecção mais apurada da circulação viral ${ }^{23}$.

Motivo pelo qual todo caso com suspeita de febre amarela deve ser transmitido imediatamente aos devidos órgãos e, após a notificação, deve-se proceder uma investigação imediata que não deve ultrapassar o período máximo de até 24 horas após a intimação, cujo resultado deve ser divulgado em até 60 dias.

Nesta perspectiva, são ações da Vigilância Epidemiológica frente a casos humanos suspeitos: 
- Detectar a maior quantidade possível de casos com suspeita (sintomáticos e assintomáticos) e notificá-los para aumentar a avaliação da população sob risco;

- Constatar casos de epizootias no território, a fim de identificar a área de risco;

- Orientar as ações para realizar o controle da epidemia (vacinação e combate ao vetor urbano);

- Salientar os resultados.

Como mencionado, a doença integra um amplo leque de diagnósticos diferenciais com agravos como a malária, hepatite, leptospirose e outras doenças ictéricas e/ou hemorrágicas, o que desfecha em um elevado percentual de casos não considerados pelos registros dos sistemas de vigilância.

Diante disto, o PVCFA recomenda a abordagem sindrômica na vigilância através do emprego de uma ficha de apuração única e da manutenção através de exames laboratoriais, como meios para apurar a oportunidade e aumentar a eficácia, a aderência científica e a caracterização do sistema de vigilância epidemiológica nacional, visando postular a vigília metódica e constante de síndrome febril ictérica e/ou hemorrágica em unidades de serviço sentinela, priorizando a aferição ampliada e recente de casos suspeitos ${ }^{23}$.

A vigilância entomológica também é uma forma de combater a doença, especialmente, através da apreensão de vetores silvestres em locais onde há ocorrência de epizootias e/ou de casos humanos.

Além disto, o reforço da capacidade laboratorial se mostra imprescindível, sobretudo, quando se considera que o princípio deste subcomponente é o melhoramento da eficácia laboratorial para a identificação antecipada do vírus da febre amarela em primatas que não sejam humanos e os próprios seres humanos também ${ }^{24}$.

Com isto, requer-se o alicerce para o diagnóstico com enfoque na pesquisa de vírus em potenciais vetores, somada à construção de dados para a detecção das espécies 
de culicídeos confinados em áreas de investigação. Vale ressaltar que, na atualidade, a rede laboratorial é advinda dos Laboratórios Centrais (LACENs), com ênfase para o Instituto Adolfo Lutz, como distingue regional e o Instituto Evandro Chagas como o laboratório de referência nacional ${ }^{30}$.

A educação em saúde é um ponto a ser mencionado, especialmente, quando se considera que esta é um mecanismo importante e que deve ocupar uma posição central nas ações de vigilância epidemiológicas, posto que é uma necessidade da população compreender de fato a doença a fim de alterar sua conduta para com a prevenção ${ }^{9,10,20,21}$.

Enfim, não se pode deixar de citar as concepções para a vigilância da febre amarela no Brasil. Nesta perspectiva, tem-se que uma das funções da vigilância epidemiológica é acompanhar o estado de saúde das populações para auxiliar as políticas públicas no sentido de propiciar locais seguros e saudáveis ${ }^{15}$, diante disto, busca-se concretizar o monitoramento da febre amarela de um viés criativo, de modo a atingir todos os inúmeros espaços de focos de proliferação da doença, os quais, uma vez detectados e mapeados, virão a ser territórios de intervenção ${ }^{13}$.

Logo, as ações neste sentido devem ser direcionadas para a melhor esclarecimento dos fatores de risco ecológicos e ambientais que articulam a circulação do vírus.

Assim, a obtenção de dados a partir da implementação de novas ferramentas e novas perspectivas devem ofertar as informações adicionais precisas para que se possa postular diretrizes de ações viáveis, as quais fundadas em bases firmes e precisas de análise e interpretação, de modo que possam gerar novas recomendações de medidas de prevenção e controle que venham, de fato, a contribuir para o melhoramento da vigilância, prevenção e controle da febre amarela no país ${ }^{20}$.

Iniciativas como estas, subsidiam a produção do conhecimento para o aperfeiçoamento da gestão e da operacionalização do sistema de vigilância epidemiológica. Com isso, deve-se aumentar o entendimento do processo de disseminação do vírus da febre amarela, levando em conta os fatores que promovem 
o risco de exposição, mecanismos de assimilação e percepção antecipadas da difusão viral a partir de primatas e vetores, e ainda esquemas que possam categorizar e diferenciar a ameaça entre as áreas predispostas e vulneráveis. Sobretudo onde os civis não são vacinados ${ }^{15}$.

Entretanto, existem ainda dificuldades severas nos municípios para assegurar o pleno avanço de um PVCFA notório e eficaz, incluindo a insuficiência de fundos de capital, problemas de capacitação laboratorial diante das demandas necessárias e ações de vigília epidemiológica, utilização incorreta dos recursos por motivo de um mau gerenciamento por políticos locais. Além dos recursos financeiros sempre escassos para o setor de saúde ${ }^{17}$.

Sendo assim, espera-se que as ferramentas já vigentes possam alicerçar a ampliação e capacitação do quadro de profissionais da saúde que disponham-se a aceitar os desafios da operacionalização e reestruturação da vigilância epidemiológica da febre amarela no país, subsidiando ferramentas para um melhor desempenho de sua função enquanto instrumento de mudança, de intervenção e de incentivo à saúde.

\section{CONCLUSÃO}

Com a urbanização dos centros rurais, cresce a possibilidade de ocorrer a emergência de certas doenças, como a febre amarela, que traria consequências sérias a saúde pública, principalmente em regiões onde o índice de cobertura vacinal é baixo.

A modificação do meio ambiente provocada pela atividade madeireira, abertura de estradas, agricultura, entre outras, expõem acidentalmente indivíduos não imunizados a vetores invertebrados selvagens, sendo uma das principais formas de transmissão da mazela na Amazônia brasileira. Tal fato constituiu-se no transcurso dos anos como uma relevante justificativa para os inúmeros casos de mortalidade ocorrida nos estados da Amazônica Legal. Até o início do ano de 2017, no Brasil, foram identificados casos episódicos ocorridos em estados localizados fora dessa área. No entanto, os primeiros meses de 2017 revelaram a necessidade de intensificar a vigilância, haja vista que a expansão do surto envolve outros Estados além de Minas 
Gerais, como por exemplo, Goiás, São Paulo e Mato Grosso, além dos Estados Amazônicos. Tal necessidade se explica pelo fato de que um paciente virulento proveniente de uma área endêmica de febre amarela silvestre poderá, associado às altas densidades do Aedes aegypti, se constituir em potencial estímulo para reurbanização da doença no Brasil. Essa afirmação é reforçada por estudos atuais, os quais indicam a presença do Aedes aegypti em cerca de 21 Estados brasileiros ${ }^{7}$, o que reforça a necessidade de vigilância.

Nesta perspectiva, surge a necessidade de um PVCFA eficiente, de modo que consiga, de fato, exercer controle sobre os possíveis focos da doença e, além disso, consiga através da educação na disciplina de saúde e da capacitação dos profissionais manter o risco de epidemia afastado da população urbana.

\section{REFERÊNCIAS}

1. VERONESI, R - Tratado de infectologia. São Paulo: Editora Atheneu, 1996.

2. COSTA, GZA; ROMANO, APM; ELKHOURY, ANM; FLANNRY, B - Evolução histórica da vigilância epidemiológica e do controle da febre amarela no Brasil. In: Rev Pan-Amaz Saude. 2011. Disponível em: http://scielo.iec.pa.gov.br/scielo.php?pid=S2176$62232011000100002 \&$ script=sci_arttext\&tIng=en. Acessado em: 01 dez. 2016.

3. MONATH, T.P - Yellow fever: an update. In: Lancet v.1, 2001, p.11-20.

4. QUARESMA, JAS - Apoptose e citocinas mediadoras da lesão hepática na febre amarela: subsídios para o redirecionamento dos mecanismos de lesão e suas consequências. 2003. 245-256f. Tese (Doutorado em Patologia Clínica) Faculdade de Medicina, Universidade de São Paulo, São Paulo, 2003.

5. LEÃO, RNQ - Doenças Infecciosas e parasitárias: enfoque amazônico. Belém: CEJUP, 1997.

6. GALLE, RP; HOFMANN, WJ; WALCZAK, H; SCHALLER, H; OTTO, GSW; KRAMMER, PH.; RUNKEL, L - Envolvement of the CD95 (APO-1/Fas) receptor and ligand in liver damage. In: J. Exp. Med. v.182, p.1223-1230, 1998. 
7. MASSAD, E; COUTINHO, FAB; BURATTINI, MN; LOPES, LF - The risk of yellow fever in a dengue-infested area. In: Trans. R. Soc. Trop. Med. Hyg. v.95, 2001, p.570-574.

8. FRANCO, O - A história da febre amarela no Brasil. Rio de Janeiro: Ministério da Saúde; 2009.

9. LACERDA, A - Em busca de um tempo perdido: fontes visuais para a história da vacina contra a febre amarela. In: BENCHIMOL, J - Febre amarela: a doença e a vacina, uma história inacabada. Rio de Janeiro: FIOCRUZ; 2010.

10. PORTO, M - Marcos técnicos e legais para a descentralização do controle de endemias. Brasília: Ministério da Saúde, 2014.

11. BENCHIMOL, J - Febre amarela: a doença e a vacina, uma história inacabada. Rio de Janeiro: FIOCRUZ, 2010.

12. BRANCO, J - Vigilância da febre amarela no Brasil. Rio de Janeiro: Fundação Oswaldo Cruz, 2008.

13. CALHEIROS, L - A febre amarela no Brasil. Rio de Janeiro: Fundação Oswaldo Cruz, 2008.

14. COSTA, GZA - Estudo das características epidemiológicas da febre amarela no Brasil, nas áreas fora da Amazônia Legal, período de 1999-2003 [dissertação]. Belém: Universidade Federal do Pará, 2005.

15. RIBAS, E - O mosquito como agente de propagação da febre amarela. Porto Alegre: Artmed, 2009.

16. SILVA, LM - Descentralização do controle de endemias. Brasília: Ministério da Saúde, 2011.

17. FARIA, GS - Endemias Rurais: métodos de trabalho adotados pelo DNERu. Rio de Janeiro: Ministério da Saúde, 2006.

18. HOMMA, A; CUNHA, J - Febre Amarela e Dengue. Rio de Janeiro: Fundação Oswaldo Cruz. 2007.

19. CAUSEY, C - Implantação dos estudos sobre arbovírus na região amazônica. 13 ed. Belém: Fundação Serviços de Saúde Pública, 2005.

20.BRASIL. Ministério da Saúde - Guia de vigilância epidemiológica. 15 ed. Brasília: Fundação Nacional de Saúde, 2012. 
21.BRASIL. Ministério da Saúde - Plano de Intensificação das Ações de Prevenção e Controle da Febre Amarela no Brasil. Brasília: Ministério da Saúde, 2008.

22. DEMO, P - Metodologia do conhecimento científico. 5 ed. São Paulo: Atlas, 2009.

23. COSTA, GZA; ROMANO, APM; ELKHOURY, ANM; FLANNRY, B - Evolução histórica da vigilância epidemiológica e do controle da febre amarela no Brasil. In: Rev Pan-Amaz Saude. 2011. Disponível em: http://scielo.iec.pa.gov.br/scielo.php?pid=S2176-

62232011000100002\&script=sci_arttext\&tlng=en. Acessado em: 29 nov. 2016.

24. LIMA-CAMARA, T.N. Arboviroses emergentes e novos desafios para a saúde pública no Brasil. In: Rev. Saúde Pública. Disponível em: http://www.scielo.br/scielo.php?pid=S0034-

$89102016000100602 \&$ script=sci_arttext\&tIng=pt. Acessado em: 25 out. 2019.

25.LOPES, N; NOZAWA, C; LINHARES, R.E.C. Características gerais e epidemiologia dos arbovírus emergentes no Brasil. In: Revista Pan-Amazônica de Saúde. Disponível em: http://scielo.iec.gov.br/scielo.php?script=sci_arttext\&pid=S217662232014000300007. Acessado em: 25 out. 2019.

26.CAMPOS, F.S. Replicação Viral. 2018. Disponível em: http://www.ufrgs.br/labvir/material/replicacao_med.pdfAcessado em: 25 out. 2019

27.BRASIL. Centro de Vigilância Epidemiológica. Sobre a Febre Amarela. 2018. Disponível em: http://www.saude.sp.gov.br/resources/cve-centro-de-vigilanciaepidemiologica/areas-de-vigilancia/doencas-de-transmissao-por-vetores-ezoonoses/famarela.html. Acessado em: 25 out. 2019.

28. GOMES, A.C; et al. Ecologia de Haemagogus e Sabethes (Diptera: Culicidae) em áreas epizoóticas do vírus da febre amarela, Rio Grande do Sul, Brasil. In: Epidemiologia e Serviços de Saúde. 2010. Disponível em: http://scielo.iec.gov.br/scielo.php?script=sci_arttext\&pid=S167949742010000200003. Acessado em: 25 out. 2019. 
29. SUCCI, R.C.M; FARHAT, C.K. Vacinação em situações especiais. In: Jornal de Pediatria. $2006 . \quad$ Disponível em: http://www.scielo.br/scielo.php?script=sci_arttext\&pid=S0021 75572006000400011. Acessado em: 25 out. 2019.

30.CAMPOS, A.C.T; MATTOS, S.V.M. Avaliação de requisitos referentes à implantação do sistema de gestão da qualidade nos Laboratórios Centrais de Saúde Pública. In: Revista do Instituto Adolfo Lutz. 2009. Disponível em: http://periodicos.ses.sp.bvs.br/scielo.php?script=sci_arttext\&pid=S007398552009000300019\&lng=pt\&nrm=iso. Acessado em: 25 out. 2019.

Enviado: Agosto, 2019.

Aprovado: Novembro, 2019. 